\title{
Opening ceremony
}

\section{Moderator (Takeshi Katsumi, JGS Secretary)}

Good morning ladies and gentlemen, thank you very much for being here, today. Welcome to Japan, welcome to Fukuoka, and welcome to this opening session of the Fifteenth Asian Regional Conference on Soil Mechanics and Geotechnical Engineering, which is organized by the International Society for Soil Mechanics and Geotechnical Engineering and the Japanese Geotechnical Society.

Before we begin with the ceremony, let me introduce the persons on the stage. Professor Jun Otani, Chairman of the Organizing Committee of this conference; Mr. Hiroyuki Suzuki, Director General of the Kyushu Regional Development Bureau, Ministry of Land, Infrastructure, Transport, and Tourism; Professor Ikuo Towhata, Vice President for the Asian Region of the International Society for Soil Mechanics and Geotechnical Engineering as well as the President of the Japanese Geotechnical Society; Professor Roger Frank, President of the International Society for Soil Mechanics and Geotechnical Engineering; and myself, Takeshi Katsumi International Secretary of the Japanese Geotechnical Society.

To officially open this conference, I would like to invite Professor Jun Otani, Chair of the Organizing Committee of the 15th Asian Regional Conference on Soil Mechanics and Geotechnical Engineering. He is a Professor from Kumamoto University in Kyushu and also serves as a Vice-President of the Japanese Geotechnical Society for 2 years starting from last June. Professor Otani please.

\section{Welcome address - Prof. Jun Otani (Chair of the Organizing Committee)}

Thank you, Mr. Chairman, and good morning distinguished guests, and ladies and gentlemen. It is a great pleasure to give you an opening speech of the 15th Asian Regional Conference under ISSMGE, International Society for Soil Mechanics and Geotechnical Engineering. In fact, we call our conference "15ARC". On behalf of the organizing committee and also Japanese Geotechnical Society, I would like to warm welcome all of you to this "15ARC" in the city of Fukuoka, Kyushu, Japan.

From now on, I would like to use the PowerPoint for my speech, so please look at the screen. First of all, about the venue here, the City of Fukuoka is a center of the western Japan market with 1.5 million population and the focal city of the Asian market which attracts many businesses and international events, and also this city is clean and safe with the rich nature of environment. And of course, somebody expect good foods. Many people know that Fukuoka is a gateway to Asian continent because it is one of the closest cities in Japan to Asian countries. I think those deserve this time of Asian regional conference here in Fukuoka, isn't it?

In fact, City of Fukuoka has a strong connection with geotechnical engineering. As some of you may know, Fukuoka is a home of "IS Kyushu" which is soil reinforcement conference under Japanese Geotechnical Society and it was held five times here in Fukuoka and many researchers and engineers around the world came to join IS Kyushu. Those events became one of good reasons for having "15ARC" here. Let me show you the four seasons in this Fukuoka from spring, summer, winter and especially now in fall. As you know, next to this conference venue, there is the event of sumo wrestling, which is one of Japanese traditional sports and you may visit this event during this conference. Fukuoka is located so called Kyushu island in Japan and as I show you in the screen, there are many attractive places in Kyushu and please try to visit those places after the conference.

Now, about this conference, we put the subtitle of this "15ARC" as the new innovations and sustainability. Of course, many of you agree that our geotechnical society always concerns about new technologies. As far as I am concerned, followings are three missions under our society. One is better life for our society; second, environmental-friendly from the geotechnical society and lastly, an innovation such as new technologies and construction activities. Besides that, we wanted to focus on one more which is "sustainability" and this is the sustainability of human resources. This is not only our society's issue but all the society's one and in order to continue our activities, definitely we need new or young members and of course, in order to be success, we need more active collaboration in Asia.

From now on, I want to show you some of the highlight of the conference programs. We have six keynote lectures, distinguished speakers, and one Mercer lecture under ISSMGE and IGS, and total 78 technical sessions, 12 topics, 12 TC sessions, and one vice-president session as you can see from the day 1 , 
day 2, and day 4. How about day 3? We put this day 3 called "Engineering Session Day (ESD)" and this is one day for engineers in which all the contents are related to engineering practice. This is under the scheme of conference subtitle. Our idea on day 3 is sustainability of human resources and also the idea of "seeds meet needs". We set another seven keynote lectures on some of the big projects in the world and one special lecture from Japan. In fact, this special lecture will be opened in public with EnglishJapanese translators, so that many people who are not our members will come in and join this session. There is one more important event which is site visit. We have two site visits and those are site visit for "15ARC" and that for ESD.

Now, I will show you one interesting statistical information about Asian Regional Conference. As you can see, this shows some statistics after $8^{\text {th }}$ Kyoto Conference until last $14^{\text {th }}$ ARC in Hong Kong. Those are the numbers of delegates, countries, lectures, and papers. How about this time, "15ARC”? As you can see this figure, the total number of delegate was 887 . In fact, this is 390 from abroad and 497 from Japan. And if we include the staff and exhibitors and others, more than 1000 people join this conference. About number of papers, total of 390 from the Asian societies and other than Asia is 90, also 32 in IGS session and 81 in TC sessions. Finally, total of 522 papers will be published in the proceedings with DOI JGS special publication, e-Journal. In addition to this number, ESD has total of 38 papers, so finally our statistics here: delegates 887 , countries 35 , lectures 15 , and paper is 560 . This means that "15ARC" had the biggest number of the delegates and also the biggest number of the paper for ARC histories.

Finally, on behalf of the organizing committee, we have to say thank you to all the member's society, national societies in Asia and all the participants. And I also want to give you our acknowledgment on the supports. First one is, as you can see here, the special thanks goes to Fukuoka city because of this venue and also Fukuoka Prefecture Government, Saga Prefectural Government and West Nippon Express Company for allowing us to have site visit. We had also several heart-warming supports and those are from International Geosynthetics Society (IGS); Asian Civil Engineering Coordinating Council; Ministry of Land, Infrastructure, Transport and Tourism Japan; Japan Society of Civil Engineers; Architectural Institute of Japan; The Japanese Society of Irrigation, Drainage and Rural Engineering; Japan Federation of Construction Contractors; Japan Geotechnical Consultants Association; and Japan Civil Engineering Consultants Association. In addition to those auspices, we had supporting associations including their offer of financial supports such as JSPS KAKENHI（No.15HP0306）; Fukuoka
Convention \& Visitors Bureau; Organizing Committee of 14th International Conference of the International Association for Computer Methods \& Advances in Geomechanics; The Maeda Engineering Foundation; Kyushu Regional Planning Association; Association for Disaster Prevention Research; Kyushu Regional Management Service Association; and 7 others. We also had total of 16 sponsorships. Without those supports, the success of this 15ARC could not have been made real and those supports are highly appreciated.

Finally, we hope all of you have very valuable discussions during "15ARC" and enjoy your stay in Fukuoka, Kyushu, Japan. Thank you for your kind attention. Thank you very much.

\section{Moderator}

Arigato Gozaimasu. Thank you very much for your opening address Professor Otani. Now, we invite Mr. Hiroyuki Suzuki. He is the Director General of the Kyushu Regional Development Bureau, Ministry of Land, Infrastructure, Transport and Tourism. Kyushu is one of the 8 regions in Japan and Fukuoka is the center of this Kyushu region. Mr. Suzuki is responsible for the land and infrastructure management in the Kyushu region and will give an address representing the local authorities. (Introducing $\mathrm{Mr}$ Suzuki in Japanese) Mr. Suzuki please.

\section{Welcome address - Mr. Hiroyuki Suzuki (Ministry of Land, Infrastructure, Transport and Tourism)}

Good morning ladies and gentlemen. Welcome to Fukuoka, Kyushu, Japan. I am Hiroyuki Suzuki of Kyushu Regional Development Bureau of Ministry of Land, Infrastructure, Transport, and Tourism, Japan.

In Kyushu, the population is 13 million. This is about $10 \%$ of Japan. The area of Kyushu is also $10 \%$. The economy in Kyushu is also $10 \%$ of Japanese GDP. Because the location of Kyushu is the gate to Asian countries, we can see, today, significant expansion of trade and rising number of tourists in growing Asian economy. So, Kyushu is a high potential region for economic growth in Japan.

From the other point of view, various disasters happen in Kyushu. Typhoon quite often hit in Kyushu. This year, two typhoons hit directly. Heavy rains caused landslides and floods. Three years ago, very significant flood disaster happened in northern Kyushu area. Also, there are 17 active volcanoes in Kyushu. Sometimes we have large scale eruption. At Sakurajima volcano in Kagoshima, we have more 700 eruptions this year. Earthquakes also happen in Kyushu. Here in Fukuoka, a big earthquake with magnitude 7 happened in 2005.

The Kyushu Regional Development Bureau create infrastructures such as road, port, and airport for 
better quality of life, and work for disaster prevention and river management against flood and countermeasures against landslide and so on.

We are living on the land. The land is the base of our lives, and the base of infrastructures. Therefore the knowledges of geotechnical engineering is one of the key factors to secure our life.

In Kyushu region, we have problematic soils such as 40-m thick Holocene very soft soil in coastal area of Ariake Sea, and Shirasu plateau consisting of volcanic ash around Sakurajima Volcano.

I believe development of geotechnology improved our life quality. Today, many geotechnical researchers and engineers gathered here with different backgrounds from different regions. I hope this conference will be a good opportunity to exchange your experience, knowledge, and ideas and make discussions for further development in your field. Thank you very much for your kind attention and please enjoy your stay in Fukuoka, Japan. Thank you.

\section{Moderator}

Arigato Gozaimasu. Thank you very much for your words, Mr. Suzuki. Now we invite Professor Ikuo Towhata to give an address as the vice-president of ISSMGE for Asia. Professor Towhata also serves as the President of the Japanese Geotechnical Society. He is Professor Emeritus of the University of Tokyo, also working with Kanto Gakuin University in Yokohama. Professor Towhata, please.

\section{Welcome address - Prof. Ikuo Towhata (JGS President \& ISSMGE Vice President for Asia)}

Good morning ladies and gentlemen. I am very happy to see so many distinguished guests, friends, and important visitors at the beginning of this important occasion for Asian geotechnical engineering community. Moreover, I am very much honoured to be here together with you after long struggling for the successful organization of this conference. I am therefore very thankful to many people who are engaged in this important mission.

I would like to spend a few minutes on my talk this morning. As Professor Otani already mentioned, we have been organizing a series of Asian Regional Conferences like this in the past. Delhi was the first host many years ago and now Fukuoka is number 15. And now, Asian Geotechnical Engineering Community has 24 member societies and I expect more will join in near future. Among these 24 friends, I believe Lebanon and Malaysia are the most recent members, so I am very happy to have these people. I checked the list of participants to find Cambodia and Philippines are already participating in this conference, so I hope these two nations will have their own member societies soon. As for outside of Asia, I am very surprised to see people coming from so many countries starting from Australia in an alphabetical order and both United Kingdom and United States. I really welcome delegates coming from nations over a long distance.

When I and my colleague organizing committee members started ideas of this congress, the key issue was what is called LCC. In this conference, LCC means low-cost conference but usually LCC means low cost carrier or aircraft. Last week I was in New Zealand and I took LCC, one typical famous LCC aircraft carrier and my flights were cancelled twice on my way to New Zealand and on my way back from Australia. So I do not recommend LCC to you. That's my experience.

On the other hand, low-cost conference is certainly nice because recently we have many international conferences which are comfortable and enjoyable. But charge is something like 800 to 1200 US Dollars. Certainly the quality of the conference deserves the high expenditure. However, some people cannot afford the fee. Particularly professors; and academicians cannot support his their own self and cannot support students' participation. That is the problem. In Asia, participation in international debate events requires long air flights as you know. From Lebanon to Fukuoka how many hours? Maybe 16 hours, 20 hours, or more than that. So travel cost is high, so registration fee should be as low as possible. That was the idea of the LCC, low-cost conference.

As for the Fukuoka conference, initially the early bird registration was only 420 US dollars; actually we were talking about 50,000 Japanese Yen and then Japanese Yen became very, very weak or US dollar became much stronger. So I regretted that we should have announced 500 US dollars at the beginning. Now, US dollar is $50 \%$ stronger than before, so this conference missed a big income unfortunately. But we promised 420, so 420 .

Anyhow, to make the conference success the number of participants have to be many. So I am very happy to have more than 800 , or 850 people registered in this conference and I hope everybody is thankful for the success of this low-cost conference.

Now let me say a little bit about our mission. I am sure you are professional and you know what you should do, but let me add something a bit different. The theme of this conference talks about sustainability. In the recent Asia, we have very quick growth everywhere. So cities are going to be much bigger and urbanization proceeds. After many years we will have the aging deterioration of the infrastructures at the same time. Already USA experienced this problem and Japan is now having such a problem. So same problem will happen in near future in all countries in Asia. When the deterioration problem occurred, USA was not prepared, Japan was not prepared, but I believe that Asia, your nations, 
will be prepared because you are already informed about this future problem.

Photo 1 shows deterioration of an old bridge in Japan. It is now out of service. It is not a geotechnical structure unfortunately.

Another mission is certainly urban transportation. In this city (Photo 2) people are riding bikes but as a human nature they want to have their own cars. The cars will occupy more space than bikes, spend more fuels and then $\mathrm{CO}_{2}$ emission will be greater. Although I am very sure that the use of car is important and convenient, we should not rely on cars too much. We have to have a good balance with road transportation and railway transportation.

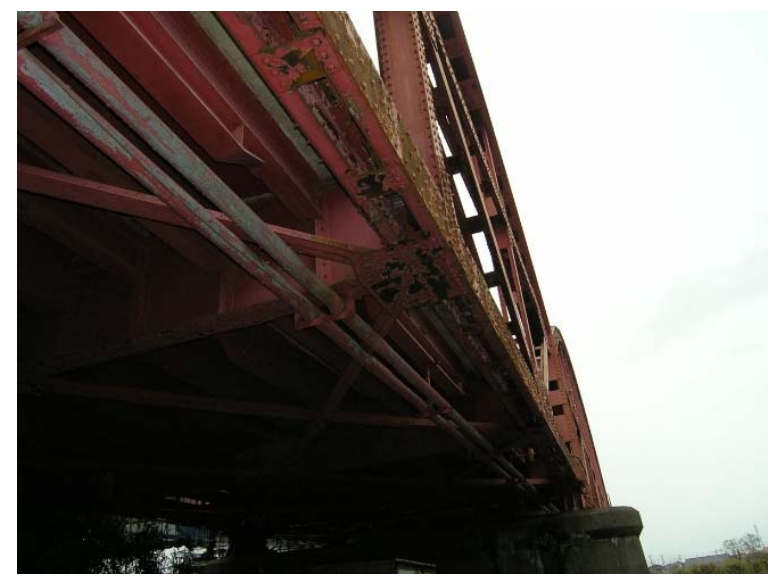

Photo 1. Deterioration of old steel bridge

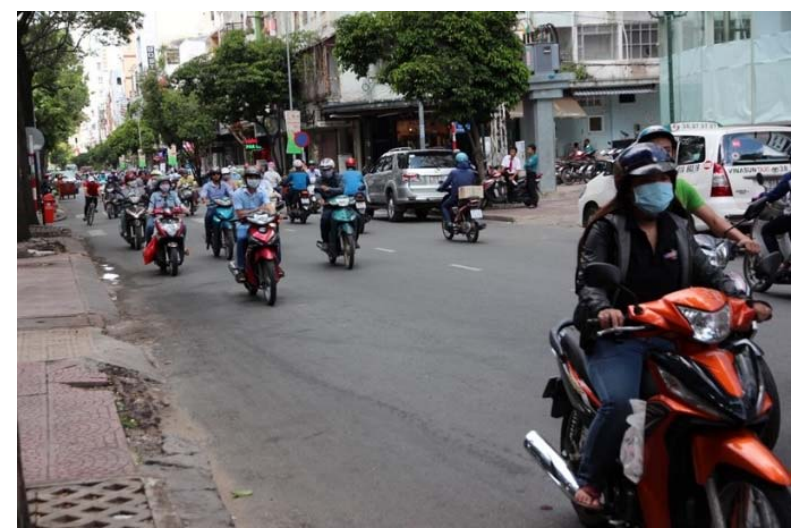

Photo 2. Motor cycles, a kind of urban transportation

Photo 3 is also from my recent travel. I love railways. Again, sustainable development requires a good balance between road and railway transportation. High speed railway is very nice. I am fond of travelling by railway over a longer distance.

Photo 4 indicates one of the Japanese railway stations. Because nature is complicated, this station is resting on an active fault. Geotechnical engineering have to cope with such natural disaster problem together with development of their own nation.

I am sure many of you have experienced working or construction of new roads. This is certainly an important mission of ours. And also water resource is a key issue, particularly in dry countries where dam construction has a long history. So there are many things we have to do. Our community expects us to do many things. Our mission is not only construction but also environmental issues including municipal waste. Waste topic includes the failure in municipal waste deposit (landfill) as well as Fukushima Number One nuclear power plant problems.

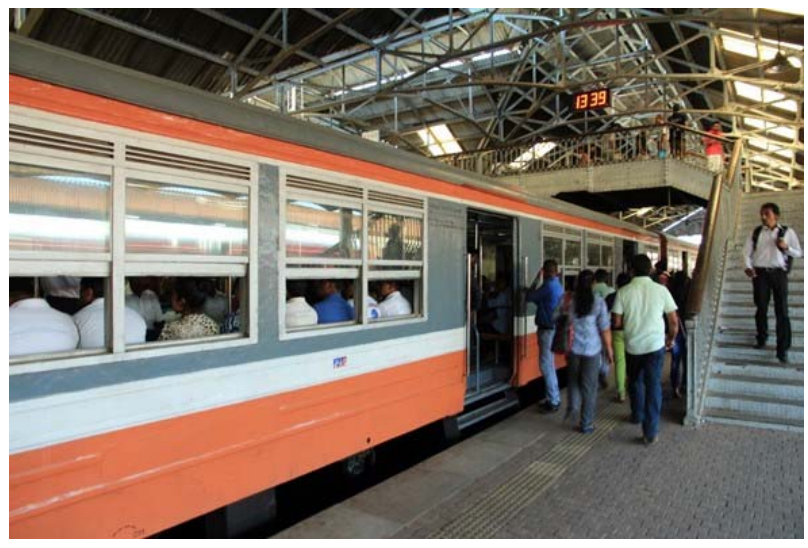

Photo 3. Importance of railway transportation

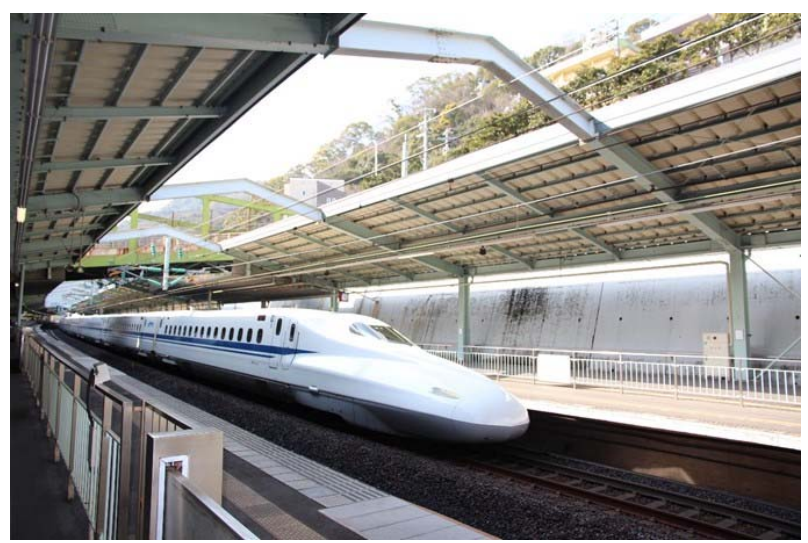

Photo 4. Station of high-speed railway

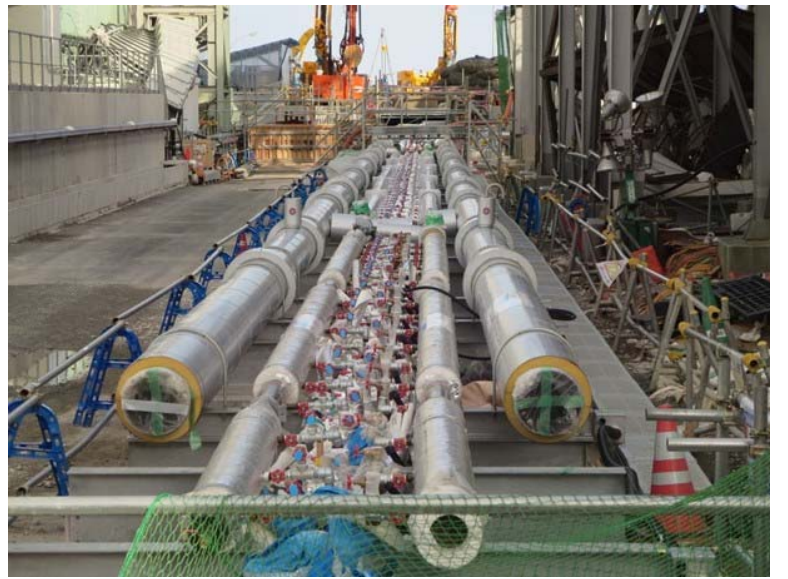

Photo 5. Attempt of frozen soil wall in Fukushima No.1 Nuclear Power Plant 
In 2015 the Japanese Geotechnical Society started a special project with governmental support for solving the Fukushima Number One Power Plant problem (Photo 5). Actually the solution of this problem will take 40 years from now on. Now geotechnical engineering is involved in solution of this serious problem.

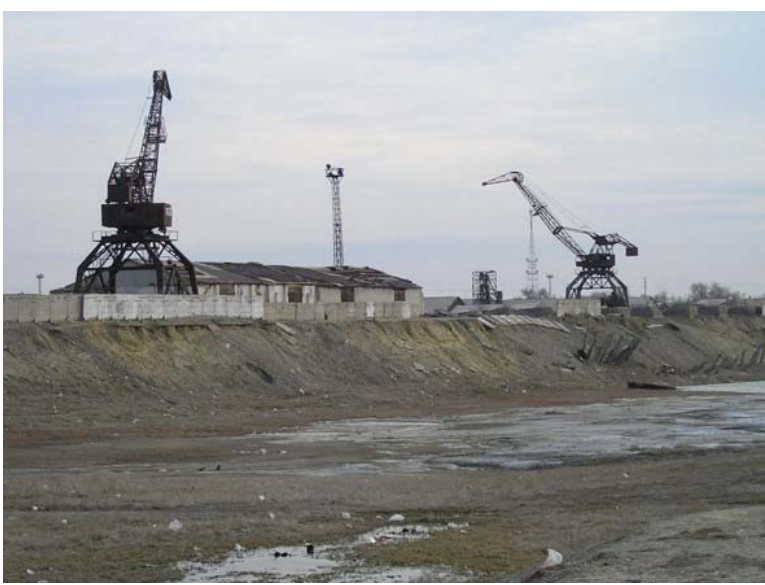

Photo 6. Harbour without water in Aral Sea

The global environmental issues are attracting concern everywhere. Professor Askar arranged me about 10 years a visit to the Aral Sea area. There was a harbour here but now no more. Also Chinese Government is doing a lot of effort to plant trees in dry areas. This effort will take time or decades. In spite of the long time needed, I am very sure that we have to do this for protection of earth.

I would like to point out that the Asian geotechnical environment is very harsh, or is harsher than the European or North American environments because we have soft soil deposits which is very thick along big rivers. Consolidation settlement is a well-known consequence of careless water pumping. Government prohibited water pumping and then water level came back to initial level again and, however, a new problem occurred in Tokyo. Two big stations underground were affected by increasing groundwater pressure at the bottom and the bottom slabs were almost broken and the entire station structures were going to come up. This was a new problem. We did not expect this type of problem before. So, countermeasures such as increasing the weight of the station and reinforcing the bottom were adopted. Thus, geotechnical engineers have to solve new problems, which is our mission.

Furthermore, certainly, we should not forget people. If people do not respect our discipline, then we will have no future; no good future to our discipline. So, we need to help people although they have shortage of money. We engineers help those who help themselves. That is called resilience.

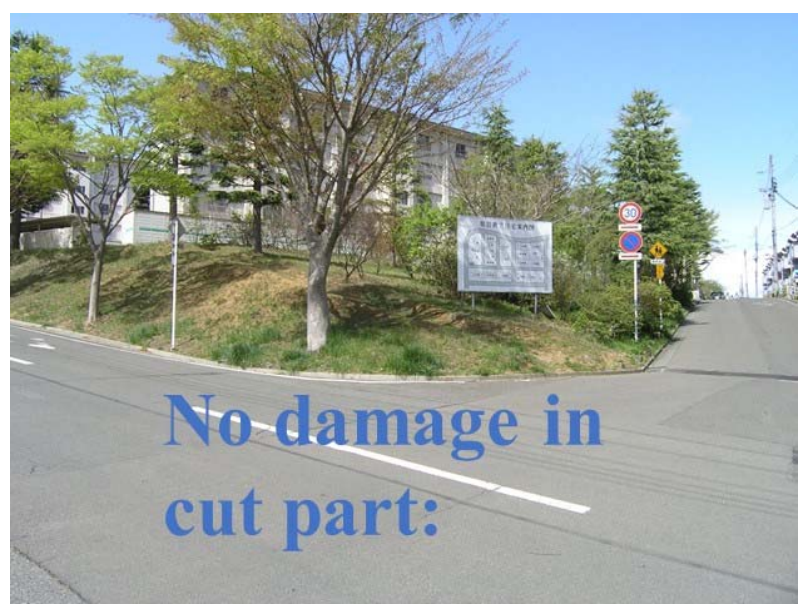

Photo 7. Intact shape of residential area in cut part

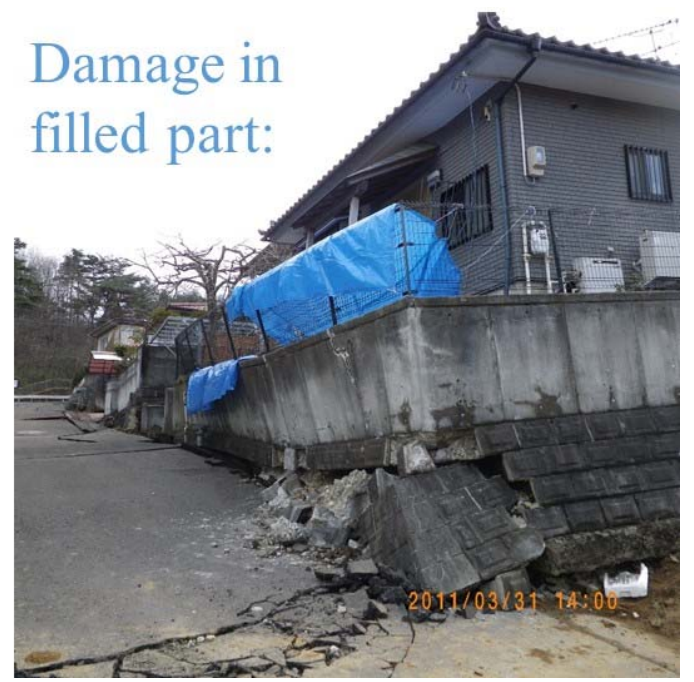

Photo 8. Significant damage in fill-part of residential area

For example, I have been involved in solution of many earthquake problems after 2011. Photos 7 and 8 show that a cut-and-fill development caused a big problem in a filled part but a nearby cut part had no problem.

People purchase land without taking care of this issue. They do not talk about bearing capacity, do not talk about strength. They do not have sufficient construction money for safe structure but we engineers still have to support them. Another important mission of ours is conservation of our historical monuments. The role of nature is significant in deterioration of historical monuments.

Humans do not know much about nature. Nature is more complicated than our knowledge. The slope in Photo 9 started to move down suddenly after a big earthquake, not during the earthquake.

Also, in Nepal, my colleagues have a big program like this because of weak geology. When I visited this area, I felt that this part was going to come down soon during heavy rain (Photo 10) and the river flow would be stopped, resulting in flooding 


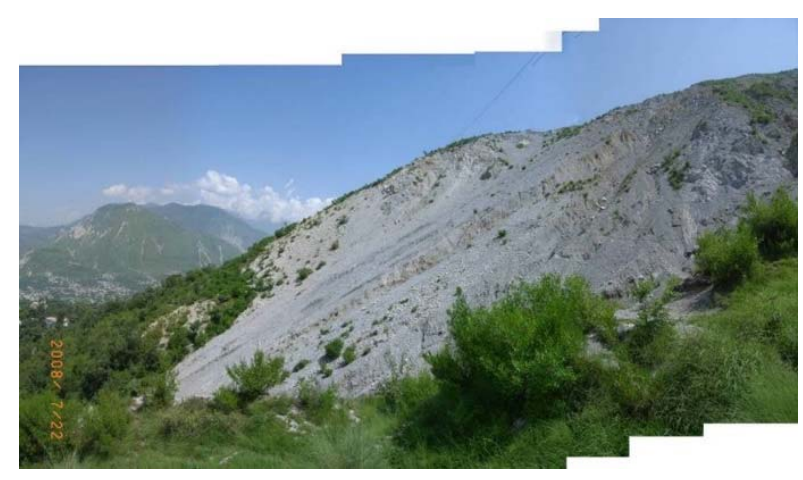

Photo 9. Slope instability that started after big earthquake

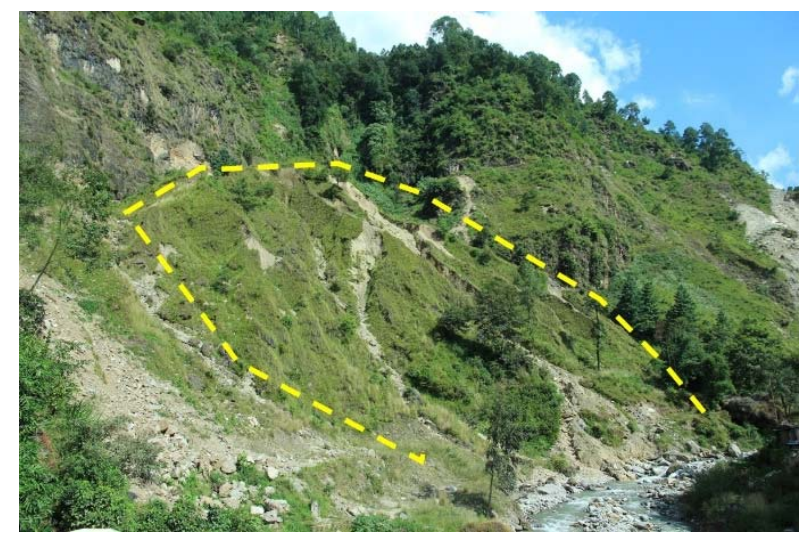

Photo 10. Unstable slope after earthquake in Nepal

Please do not forget the Seoul Conference in 2017. Asian colleagues should make this important event successful, which is our obligation to the international geotechnical community. Also, next year, Kazakhstan Society will host the Asian Young Geotechnical Engineer Conference.

Thus we have so many things to do but engineers can do their best. I would like to recall you on Sri Lanka. The Sri Lankan geotechnical engineering is now developing very fast. This is very nice because the nation finished internal war several years ago. Peace gives us a good stage to work.

At the end, I would like to thank you very much for your kind attendance in this conference. Please enjoy this week in Fukuoka. Thank you very much.

\section{Moderator}

Thank you very much for your address, Professor Towhata. Today, we are also very fortunate to have here our president, Professor Roger Frank, who came all the way to Japan despite a long distance. Thank you very much, Mr. Frank. Professor Roger Frank is an Honorary Professor of École Nationale des Ponts et Chaussées, in Paris, France which is called National School of Bridges and Highways, in English, and serves as president of ISSMGE for the time period from 2013 to 2017. So we would like to invite Professor Frank to give us the presidential address.

\section{Presidential address - Prof. Roger Frank (ISSMGE President)}

Good morning ladies and gentlemen, good morning dear colleagues. I would like to express first my thanks to the Japanese Geotechnical Society, to Professor Jun Otani, to Professor Ikuo Towhata and the organizing committee for having given me the honour to be with you at this conference.

It is also a great pleasure to be in Japan, to be in Asia and to have this opportunity to meet the many friends I have in this region and the opportunity to make new friends in this region. This conference promises to be a very great success. We see the quality of the organizing committee, the quality of the attendance, the quality of the written contributions, and of course the magnificent city of Fukuoka and the beautiful island of Kyushu where I understood the nature gives a lot of work to geotechnical engineers!

Ikuo, you have already proved that LCC, low-cost carriers do not work, but LCC low cost conferences could work very well. Thank you!

Just a few words about the International Society for Soil Mechanics and Geotechnical Engineering. Well, I remind many of you that the ISSMGE is the pre-eminent professional body representing the interest and activities of engineers, academics, and contractors all over the world that actively participate in geotechnical engineering.

Our main goal is to contribute to the development of knowledge, education, and cooperation. You probably already know there are no commercial or political interests in the ISSMGE. We are 89 member societies (out of which 24 are in Asia), representing 20,000 individual members. In the Japanese Society there are 1200 members which makes it a very important member society. Very quickly, I must just inform you that the present tools of the ISSMGE are national, regional, international conferences, the ISSMGE bulletin, which is online every other month, the webinars delivered by experts in their field, the journal of case histories and the professional network called 'Geo-World'. And also perhaps more importantly we have 35 technical committees which are really the working forces of the ISSMGE.

These technical committees are devoted to some specific issues which were mentioned this morning. The ISSMGE member societies are organised in geographical regions. We have six regions. For each region there is an ISSMGE Vice-President who plays an important role in the region. He or she has the responsibility of representing the member societies of the region. These regions are Africa, Asia - we have Vice-President for Asia, Professor Ikuo Towhata, with us here, one of the organizers of this conference -. Australasia, Europe, North America, and South America. We consider regional activities as very important like the Asian regional conference and 
other regional conferences. They are able to attract not only many people from the region but also people from outside the region and this is a very good thing a regional conference can achieve also.

Now, 2015 is a special year, as it is the mid-term year, the mid-term of the president, and more importantly the mid-term of our activities between the two international conferences, the one in Paris in 2013 and the one is Seoul in 2017.

So far three regions have had their regional conference. Australasia was in February in Wellington in New Zealand, Africa was in Hammamet in Tunisia in April. We had the European one in Edinburgh in the UK in September and we are now in Japan in Fukuoka on the island of Kyushu for the Asian one. And in a few days' time, and some of us will meet again there with great pleasure, we shall have the Pan-American Conference in Buenos Aires, Argentina.

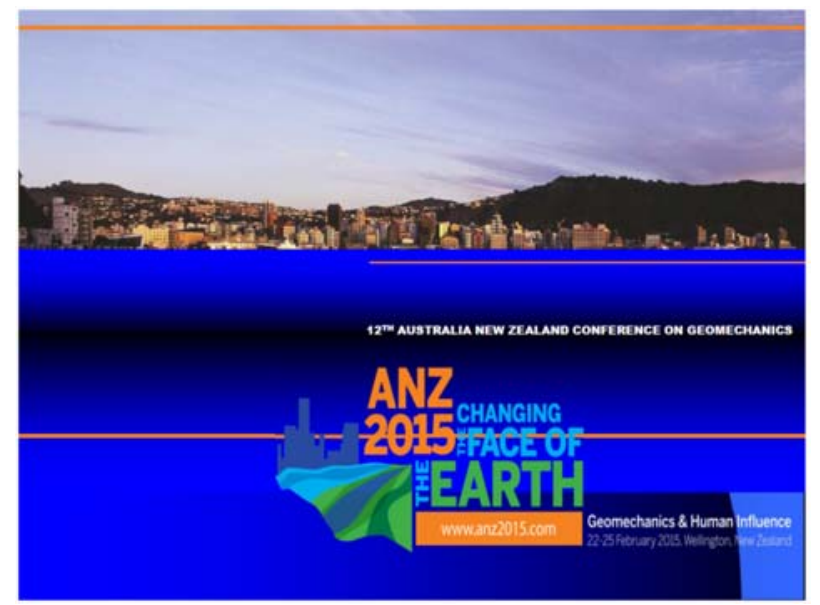

Figure 1. Slide for the 12th Australia New Zealand Conference on Geomechanics

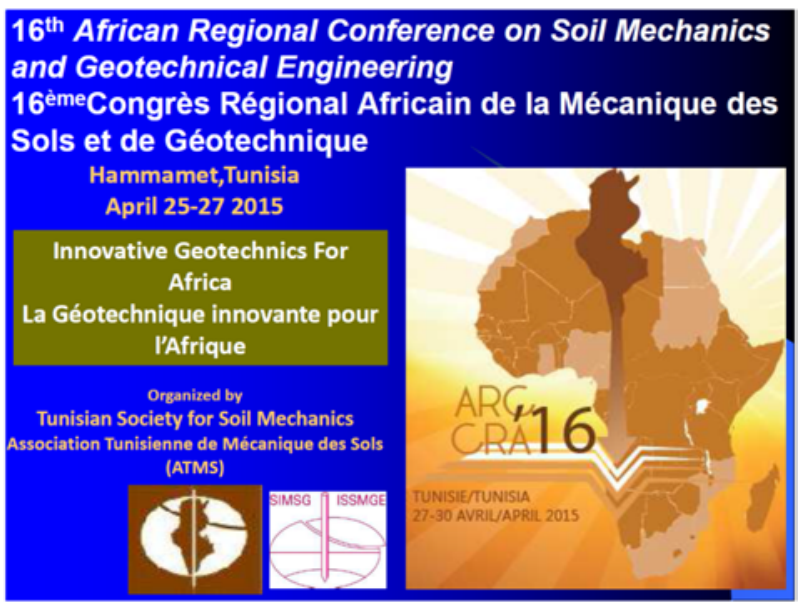

Figure 2. Slide for the 16th African Regional Conference on Soil Mechanics and Geotechnical Engineering

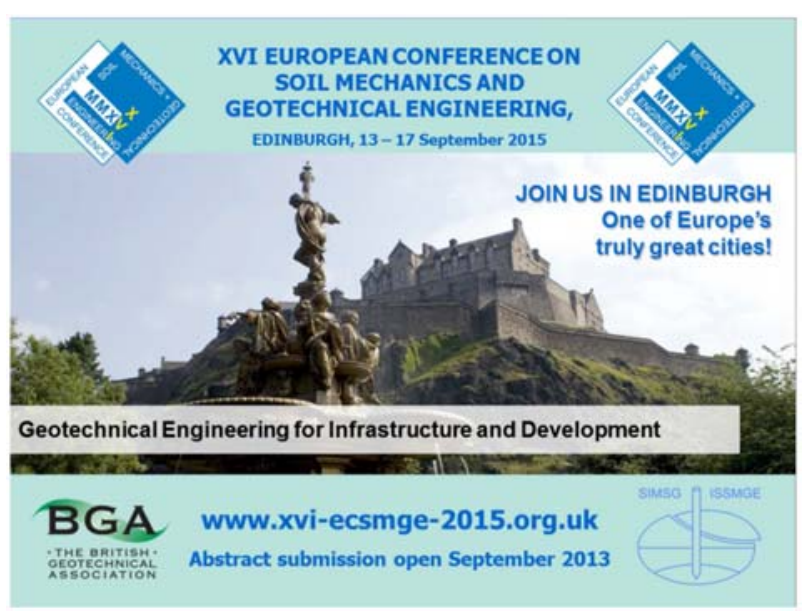

Figure 3. Slide for the 16th European Conference on Soil Mechanics and Geotechnical Engineering

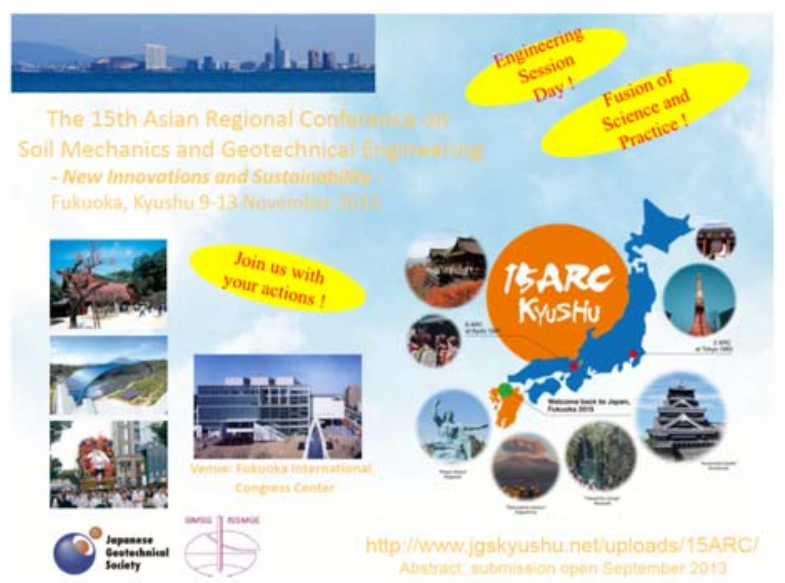

Figure 4. Slide for the 15th Asian Regional Conference on Soil Mechanics and Geotechnical Engineering

Just a few slides. One slide per conference: you have the beautiful view of Wellington for the Australasia (Australia-New Zealand) conference. Interesting to see is also the topic of these conferences; for Wellington it was "Changing the face of the Earth" (Figure 1).

The African one in Hammamet, Tunisia, was "Innovative Geotechnics for Africa” (Figure 2).

In Edinburgh it was "Geotechnical Engineering for Infrastructure and Development” (Figure 3).

We are in Fukuoka, Kyushu, Japan for "New Innovations and Sustainability" as mentioned earlier (Figure 4).

The next one will be in Buenos Aires and it will be in fact the gathering of three different conferences: the Pan-American conference of the ISSMGE which is of course the most important one of the three, but there will also be the South American Congress on Rock Mechanics and the International Symposium on Deformation Characteristics of Geomaterials, which is an international symposium organized by the technical committee TC 101 of the ISSMGE (Figure 5). 


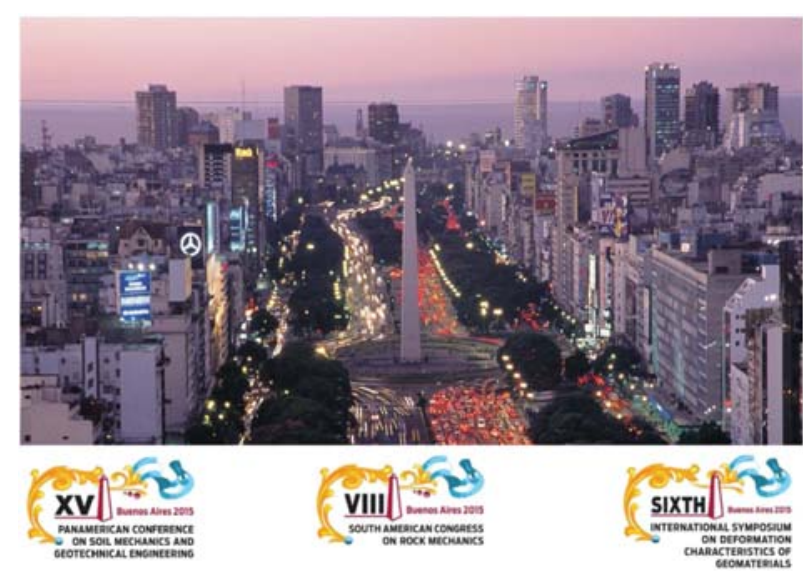

Figure 5. Slide for the 15th Pan-American Conference on Soil Mechanics and Geotechnical Engineering

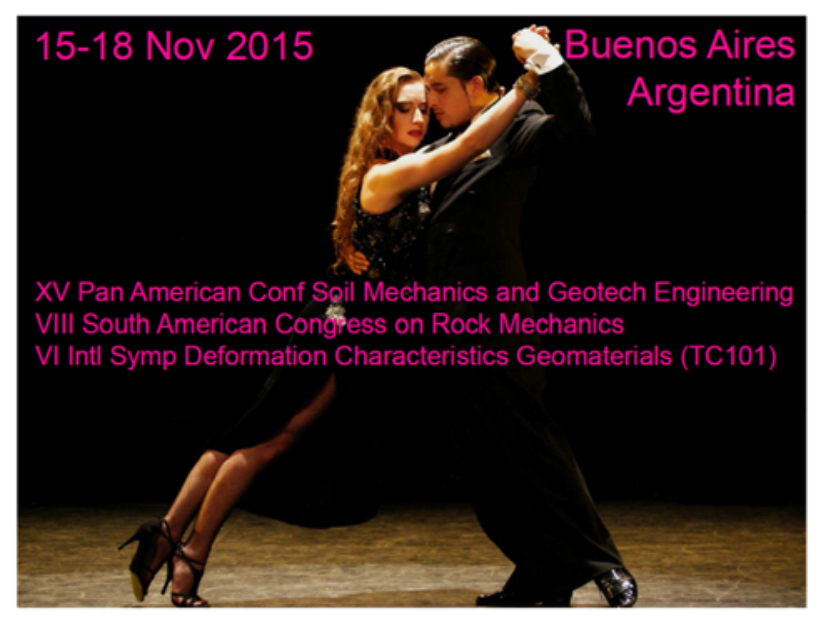

Figure 6. Slide for the 15th Pan-American Conference on Soil Mechanics and Geotechnical Engineering

And even more appealing for some of us in South America is probably to have some tango and this is also a way of attracting some of you to this conference! (Figure 6)

The year 2015, indeed, is half way between the Paris conference and the next international conference, which will be held in Seoul (Figure 7). We are happy to have our friends, organizers from Korea with us in Fukuoka and don't hesitate to communicate with them. There is a booth as well where you can have more information about this conference and I expect, we all expect that the participation from Asian countries will be of course the most important one. And especially it is not far from Japan, not either from China or some other countries of Asia. Anyhow, Asia is nearer than Europe so please come to this conference, I shall be there of course!

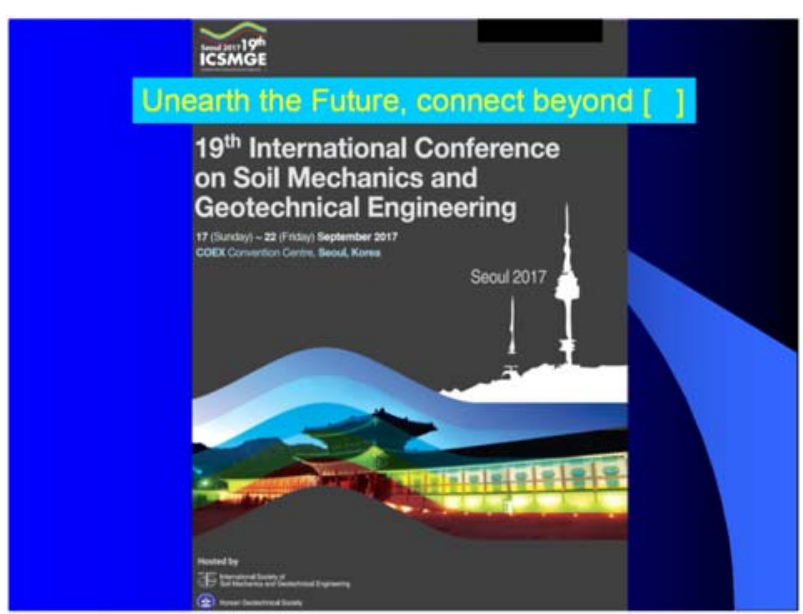

Figure 7. Slide for the 19th International Conference on Soil Mechanics and Geotechnical Engineering

And interesting enough is the topic of this conference: "Unearth the Future, Connect Beyond", it is a great title. In fact to be quite honest, I have been struggling for weeks or months now to know how I am going to translate it into French. This is the only job I have to do for this conference, it is to translate the title in French. Our Korean colleagues are dealing with everything. I am most grateful to them. It is a wonderful title, it is provocative. It is what these conferences should do. They should provoke us!

Let us come back to Fukuoka. We are looking forward to a very successful conference. Have a successful conference! Enjoy your stay in wonderful Fukuoka in this very nice building and also outside. And of course if you have more time, I think that it is also an excellent thing to enjoy the island of Kyushu. Thank you for your attention!

\section{Moderator}

Thank you very much, Professor Frank. Thank you all for your opening and welcome addresses. Now we are happy to officially open the 15th ARC. And let us take a very brief break because I would like to pass this microphone to Professor Askar Zhussupbekov, our immediate past vice-president, will moderate first plenary session. So you are all kindly invited to stay here for the first plenary session. Thank you very much. 